\title{
A INTEGRAÇÃO DOS DIREITOS HUMANOS NO MERCOSUL
}

\section{THE INTEGRATION OF HUMAN RIGHTS IN MERCOSUR}

Leila Maria Da Juda Bijos ${ }^{1}$

Gleidson Bonfim da $\mathrm{Cruz}^{2}$

\section{Resumo}

O presente trabalho suscita a possibilidade de elaboração de uma declaração de direitos humanos aplicável aos países integrantes do Mercado Comum do Sul - MERCOSUL - gerada a partir das ideias oriundas do transconstitucionalismo, teoria que unifica os ordenamentos constitucionais dos Estados sob a premissa dos direitos humanos existentes e aplicáveis em cada país. A relevância da pesquisa está embasada nos benefícios oriundos da declaração de direitos humanos, uma vez que, através da positivação dos direitos humanos aplicáveis aos Estados Membros do MERCOSUL seria possível elaborar pactos no sentido de sancionar aqueles que não observassem a declaração. O trabalho está embasado numa metodologia de pesquisa hipotético dedutiva.

Palavras-chave: Direitos humanos; Transconstitucionalismo; Estados; Bloco econômico.

\begin{abstract}
The present work raises the possibility of elaborating a declaration of human rights applicable to the member countries of the Southern Common Market - MERCOSUR - generated from the ideas derived from the transconstitutionalism, a theory that unifies the constitutional systems of the States under the premise of existing human rights applicable in each country. The relevance of the research is based on the benefits generated by the declaration of human rights, since by enhancing the human rights applicable to MERCOSUR Member States, it would be possible to elaborate pacts in order to punish those who did not observe the declaration. The work is based on a hypothetical deductive research methodology.
\end{abstract}

Keywords: Human rights; Transconstitutionalism; States; Economic Block.

\footnotetext{
1 Pos-Doutora pela Saint Mary's University, Halifax, Nova Scotia, Canada. Professora Associado do Mestrado em Propriedade Intelectual e Transferência de Tecnologia para Inovaçao, Universidade de Brasília. Coordenadora do Grupo de Pesquisa "Laboratório de Política Internacional", e da Linha de Pesquisa em Direitos Humanos. É membro da Cátedra da UNESCO de Juventude, Educação e Sociedade. Pesquisadora Visitante da Universidade de Hyderabad, Índia; do Programa de Doutorado em Economia Internacional da Universidade de Tsukuba, e da University of Califórnia, San Diego (UCSD). E-mail: leilabijos@gmail.com

2 Mestre em Direito Internacional pela Universidade Católica de Brasília. Professor dos Programas de Direito da Universidade Católica de Brasília e do Centro Universitário IESB. E-mail: gleidsonbcruz@hotmail.com
} 


\section{INTRODUÇÃO}

O presente artigo tem como objetivo demonstrar a possibilidade de integração entre os países componentes do Mercado Comum do Sul - MERCOSUL através de um núcleo constituinte único focado nos Direitos Humanos, tendo em vista que no atual cenário internacional se faz mister uma clareza quanto à proteção de tais direitos para que se obtenham melhores condições negociais aos atores dos embustes internacionais.

O grande entrave para se falar em proteção de Direitos Humanos na América do Sul foi o longo período de ditadura militar, que se estabeleceu nas duas principais potências, Brasil e Argentina, momento histórico em que pouco se pensava na proteção individual da população.

Com o intuito de gerar um pensamento protetivo para a humanidade focado em um eixo jurídico unificado, surgiu a figura do transconstitucionalismo prevendo ser possível que se buscasse a união entre os centros comuns dos ordenamentos jurídicos existentes nos países, no que se refere às medidas protetivas dos direitos humanos, pois segundo esta teoria, haveria como integrar os distintos sistemas constitucionais ora vigentes.

Por outro lado, sopesar o caráter soberano de cada país integrante do bloco econômico, a fim de depurar como se dá a aplicabilidade dos direitos humanos em cada território é tarefa não muito simplória, pois por se tratarem de países com graves problemas sociais os mesmos tendem a mascarar das comunidades internacionais o real caráter das condições em que as populações são de fato tratadas.

Percebe-se aqui que, para que haja uma eficaz proteção aos direitos humanos, os Estados-membros do MERCOSUL deveriam abrir mão de obtenção de melhores condições econômicas para gerar ao seu povo as garantias inerentes à dignidade da pessoa humana. A consecução de um bom resultado econômico não seria fator fundamental se para tal resultado fosse necessário causar um dano direto à população ora envolvida.

Países membros do MERCOSUL com economias mais fortes, bem como com população maior, como o Brasil e a Argentina, por estarem em foco direto das ações das comunidades internacionais deveriam tomar posturas mais ativas, no sentido de proteger os direitos fundamentais de suas populações. Percebe-se, portanto, que esses atores são de importância ímpar para que haja uma eficaz proteção aos direitos humanos no bloco do MERCOSUL.

A relevância que os direitos humanos têm tomado nos interesses dos países integrantes do MERCOSUL fora a recente suspensão da Venezuela sob o argumento de esta não estar respeitando a democracia e cometendo atentados diretos à sua população. 
No ano de 2017, o caso da suspensão do Estado Venezuelano da integração do MERCOSUL acabou por ser paradigmático no sentido de demonstrar que a comunidade internacional se preocupa com o tratamento que será dado aos seus cidadãos, quando estes transitarem por países que estejam com dificuldades de garantir a proteção dos direitos humanos, até porque estes indivíduos acabariam por ter sob ameaça alguns de seus principais direitos, principalmente os patrimoniais e pessoais.

Um núcleo único formador de uma teoria constitucional interna coesa, fundamentada em direitos humanos específicos seria, de sobremaneira, suficiente para que se evitasse a ocorrência de rupturas como as ocorridas no estado Venezuelano, partindo da premissa que um texto constitucional comum exarado em esfera internacional, além de permitir uma melhor compreensão do que seriam os direitos humanos em ambiente nacional, trariam à baila uma série de fatores protetivos às populações dos países integrantes do MERCOSUL.

A partir da Declaração Universal dos Direitos Humanos, que vigora desde 1948, se tornou possível que se regulamentassem os direitos humanos, no entanto, os pactos suplementares foram surgindo de formas aleatórias, e acabam por não serem precisos quanto às ações afirmativas que são cabíveis aos Estados que a eles se submetem.

Para a garantia de um MERCOSUL que observe de fato os direitos humanos, seria necessário que se fizesse uma análise transconstitucional, buscando os núcleos constitucionais comuns e se elaborasse um pacto unificador de Direitos Humanos onde os Estados-membros pudessem ter uma baliza internacional robusta, que propusesse medidas eficazes para a consecução de resultados de fato garantidores da ordem humana internacionalmente perquerida. Em um primeiro momento, as cortes europeias, que tratam da aplicabilidade dos direitos humanos, poderiam servir de espelho, para a elaboração de uma declaração focada no MERCOSUL, mas as realidades culturais e econômicas do bloco americano não são similares às da Europa, por este motivo o ideal seria a especificação e quais seriam os direitos comuns aplicáveis aos cidadãos do MERCOSUL e, posteriormente, a redação de normas que conferissem a ele exigibilidade.

Como objetivo do presente estudo e através da metodologia de pesquisa hipotético dedutiva, tem-se que a elaboração de uma declaração de direitos humanos aplicável aos países integrantes do MERCOSUL geraria a possibilidade de uma melhor interação entre os atores internacionais ligados ao bloco, uma vez que seriam claros os direitos que deveriam ser protegidos e, a partir disso, pactos sancionadores poderiam ser redigidos com o intuito de que 
os Estados membros pudessem ser diretamente responsabilizados caso gerassem alguma lesão a nichos populacionais.

$\mathrm{Na}$ atual conjuntura dos direitos humanos regionais inexiste um rol declarativo dos direitos das populações integrantes do MERCOSUL, por este motivo não se pode cobrar ações diretas dos Estados membros para que de fato protejam tais direitos. A pesquisa propõe que estes direitos sejam declarados a partir de um núcleo comum com a ideia transconstitucional, possibilitando assim à comunidade internacional alguma espécie de fiscalização e de coerção frente àqueles que gerarem danos diretos aos povos integrantes.

\section{TRANSCONSTITUCIONALISMO}

O direito constitucional dos países é visto como o ramo do direito público com maior relevância para nortear as relações intersociais e entre o povo e o Estado, esta seara do direito acaba por se mostrar como essencial no núcleo formador das orientações de atuação dos Países.

A fim de que haja uma melhor concepção sobre a importância dos textos constitucionais na ordem interna de cada Estado faz-se necessária uma conceituação lógica do que seria uma constituição, no entanto, por seu grau de importância, não é possível que se encontre uma definição linear simplificada do que viria a ser um regramento constitucional, para tanto, Ferdinand Lassalle já deliberou: "Em todos os lugares do mundo e em todas as épocas sempre existiu e sempre existirá isso que chamamos de Constituição" ${ }^{3}$. Assim, percebese que o texto constitucional é algo que se faz presente desde quando a sociedade começou a se organizar de forma complexa.

O direito constitucional pode ser conceituado como sendo o ramo do direito que traz os regulamentos sociais, políticos e jurídicos, além do que, podem-se chamar, como direitos fundamentais a serem aplicados a uma nação constituída formalmente e estruturada em território e povo ${ }^{4}$.

A partir da premissa que as Constituições são o núcleo legislativo formador dos Estados organizados, procura-se, dentro deste núcleo, o que poderia ser foco comum da maioria dos Estados que possuem pensamentos paritários. Na parte ocidental do globo, os países líderes dos blocos econômicos, há tempos debatem as formas de como tornar eficaz a aplicabilidade

\footnotetext{
${ }^{3}$ Digressão desenvolvida propedeuticamente por Ferdinand Lassalle em seus estudos - 1863.

${ }^{4}$ CARVALHO, Kildare Gonçalves. Direito Constitucional. 21a Ed. Belo Horizonte: Del Rey, 2017, p. 1
} 
dos Direitos Humanos, de maneira linear e planificada, tendo em vista que uma crise humanitária não afeta apenas um povo e sim o ser humano como um todo, o que pode ser percebido na ideia originária no pós-guerra que gerou a Carta Internacional dos Direitos Humanos ${ }^{5}$.

Os Direitos Humanos são os núcleos de direitos que exprimem a relação entre o ser humano e o princípio da Dignidade da Pessoa Humana, ou seja, buscou-se uma gama de pretensos direitos, atemporais e translocais que poderiam ser aplicados a todo e qualquer ser humano a fim de que se garantisse que o homem tivesse condições mínimas para possuir uma vida que Ihe permita convivência digna com uma ideia de bem estar médio ${ }^{6}$.

O que se sobrepõe à ideia de consecução dos direitos humanos nas sociedades modernas é a busca pelo poder por parte dos governantes, e dos governos, dos diferentes Estados, ou seja, no afã de se tornar poderoso o Estado acaba por mitigar direitos que concedam uma vida minimamente aceitável para a sua população ${ }^{7}$.

Com o desenvolvimento social moderno e com as tendências de globalização, os direitos humanos deixaram de ser um problema de implementação e aplicação local para uma seara mais ampla, tendo em vista que extrapolavam as fronteiras dos Estados e se enraizavam em outros sistemas, até porque tendem a ser universais.

A aplicabilidade dos Direitos Humanos passou a ser objetivo de países distintos com ordens constitucionais distintas, o que culminou por aproximar ordenamentos jurídicos que em sua origem não poderiam ser vistos como integrados ou, sequer, relacionados. Ocorre que, embora os países tenham ordens constitucionais fundamentadas em sua soberania, estes não mais poderiam se fechar para resolver questões inerentes aos direitos humanos de forma isolada, tendo em vista que muitas vezes os danos causados ao ser humano nos limites do território de cada país feririam a honra de qualquer cidadão mundial.

As diversas constituições existentes trazem em seus textos menções claras aos direitos humanos, reiterando a ideia de que estes direitos estão tipificados de forma direta e clara em uma gama de ordenamentos constitucionais. Segundo a doutrina moderna, os direitos humanos são constitucionalmente formais quando estão claramente prescritos nos textos magnos de um

\footnotetext{
${ }^{5}$ RAMOS, André de Carvalho. Curso de Direitos Humanos. 4ạ Ed. São Paulo: Saraiva, 2017. p.154.

${ }^{6}$ Idem, p. 21.

${ }^{7}$ MENDES, Gilmar Ferreira e Paulo Gustavo Gonet Branco. Curso de Direito Constitucional. 12a Ed. Rev. e Atual. São Paulo: Saraiva, 2017, p. 163.
} 
Estado, por outro lado seriam materialmente constitucionais se, mesmo sendo previstos em um ordenamento jurídico, não constem expressamente no texto constitucional concebido ${ }^{8}$.

A partir da edição, em 1948, da Declaração Universal dos Direitos Humanos, carta da ONU, que apresentou 30 artigos clarificando o que seriam Direitos Humanos passou a ser possível analisar os textos constitucionais e deliberar quais constituições contemplavam aquela seara específica de direitos ${ }^{9}$. Além disso, passou a ser possível saber quais Estados efetivamente garantiam aqueles direitos e quais não estavam sendo eficazes em proteger a sua aplicabilidade direta.

A Declaração Universal dos Direitos Humanos permitiu que fosse possível que se verificasse o núcleo de dificuldades comuns, inerentes à aplicabilidade do rol de direitos humanos por parte de diferentes Pessoas Jurídicas de Direito Público Internacional, aproximando as constituições em torno de um denominador comum que seria a garantia de observância dos direitos humanos.

Entre diferentes núcleos constitucionais afloram os mesmos tipos de problemas, que muitas das vezes prescindem das mesmas respostas. Nesta senda, no âmbito interno de cada país, os direitos humanos acabam por necessitar de uma especificação mais detalhada, nos termos de José Afonso da Silva (2008), pode-se inferir que a aplicação interna dos Direitos Humanos seriam os Direitos Fundamentais, pois estes demonstrariam situações sem as quais as pessoas humanas não teriam, sequer, muitas das vezes, a chance de sobreviverem ${ }^{10}$. Ora, a proximidade dos conceitos de Direitos Humanos e de Direitos Fundamentais demonstram que os institutos visam tutelar o mesmo bem jurídico, ou seja, o ser humano.

Ocorre que nem sempre os ordenamentos jurídicos internos, mesmo com o respaldo de institutos externos, são suficientes para resolver problemas inerentes aos direitos humanos. Nesta brecha surge o que se pode definir como transconstitucionalismo que nada mais seria do que uma tentativa de aproximação de núcleos constitucionais distintos cujo objetivo visava à elaboração de uma linha similarizada de aplicabilidade dos direitos focados na pessoa humana, e nos resultados de centros unificados de diversas ordens constitucionais que gerem a obtenção de melhores focos protetivos. Para Marcelo Neves os problemas internos referentes aos direitos humanos podem ser vistos como transconstitucionais quando relacionam órgãos do

\footnotetext{
${ }^{8}$ RAMOS, André Carvalho. Curso de Direitos Humanos. 4a Ed. São Paulo: Saraiva, 2017, p. 22.

${ }_{9}^{9}$ UNIC, Rio. 2009. Disponível em: < http://www.onu.org.br/img/2014/09/DUDH.pdf> Acesso em: 26 de janeiro de 2018.

${ }^{10}$ SILVA, José Afonso da. Curso de Direito Constitucional Positivo. 31a Ed. São Paulo: Malheiros, 2008, p. 178.
} 
poder judiciário interno, bem como, organismos judiciais internacionais, entrelaçando assim ordenamentos jurídicos distintos ${ }^{11}$.

Pode-se definir o transconstitucionalismo como sendo uma modalidade de cuidados constitucionais que unificam problemas em torno do mesmo núcleo satisfativo, ou seja, seria o instituto um meio de integrar ordenamentos jurídicos constitucionais distintos, unificados pelos Direitos Humanos, objetivando a solução de problemas comuns que transcendessem as fronteiras de cada nação.

O intento do constitucionalismo seria, então, um aporte transfronteiriço que unificasse sistemas constitucionais, partindo-se da premissa de que se houvesse a integração entre os ordenamentos jurídicos, fatalmente haveria a fortificação dos Direitos Humanos em escala global, e não somente regional como é o caso dos Direitos Fundamentais. Insta asseverar que os direitos fundamentais, por estarem, em sua maioria, positivados no texto constitucional, em seu âmbito formal ou material, já integram sistemas jurídicos distintos. No entanto, ao serem aplicados de forma isolada, apenas em um ordenamento jurídico específico de um país, acabariam por perder eficácia e, em se tratando de âmbito regional, ou até mesmo global, perder significância.

Por outro lado, algumas dificuldades surgem ao se falar em um núcleo internacional focado na consecução de resultados diretos afetos aos direitos humanos, tendo em vista que os Estados tendem a fechar suas soberanias e fortificar sua ordem interna em detrimento de ordens internacionais, até porque o principal contraponto dos referidos direitos seriam, diretamente, o poder estatal. A dicotomia existente entre a ordem interna e a anarquia internacional acabaria por dificultar uma apreciação conjunta de núcleos distintos mesmo que focados no mesmo centro, entendendo-se que a anarquia internacional se parte da premissa de que inexiste uma autoridade centralizadora que seria capaz de delimitar conceitos e estabelecer um foco regimentalizado de condutas ${ }^{12}$.

O foco do transconstitucionalismo parte de uma premissa de diálogos jurídicos entre os atores internacionais, para que se fortaleça um núcleo constitucional focado na mesma ideologia de defesa do que há de mais importante nos Estados que seria a sua população. Até porque o ponto comum, pautado nos direitos fundamentais, insurge como sendo algo inequívoco dos diversos centros de constitucionalidades.

\footnotetext{
11 NEVES, Marcelo. Transconstitucionalismo. São Paulo: Martins Fontes, 2009, p. 22.

${ }^{12}$ AMARAL JÚNIOR, Alberto do. Curso de Direito Internacional Público. 3ạ Ed. São Paulo: Atlas, 2012, p. 01.
} 
O que é temido quando se aborda uma questão conflitante afeta aos direitos humanos na seara internacional seria a delineação de uma linha racional única ligada a transversalidade do ramo do direito que se busca, por outro lado a multiculturalidade dos atores, ora envolvidos, acabaria por trazer um empecilho a um núcleo comum, tendo em vista que poderia distanciar linhas humanitárias delineadas e apregoadas pelos diversos Estados.

Para que haja um transconstitucionalismo é necessário que se fortaleçam os direitos fundamentais da ordem interna, pois se um Estado possui medidas protetivas de seus direitos fundamentais em um grau mais elevado do que outro, tal desequilíbrio poderia gerar insegurança àqueles atores. Para que haja uma maior proteção aos Estados que se relacionam, as garantias constitucionais existentes nas ordens internas de cada um deles acabam por influenciar o caráter transconstitucional em debate, tendo em vista que um aspecto transconstitucionalista meramente formal ao qual o alinhamento prático não está no mesmo patamar das ideias codificadas acaba por distanciar as realidades regulamentares dos países pares.

A partir da evolução da proteção de direitos humanos, caso determinado Estado não esteja fornecendo à sua população as garantias básicas possibilitadoras de uma vida digna, e este Estado esteja se distanciando dos núcleos comuns à sociedade internacional, atribui-se ao indivíduo a capacidade postulatória especial para questionamentos específicos de tais direitos em seara internacional, pois alguns organismos de proteção internacional terminam por conferir a possibilidade à pessoa física de se buscar a proteção de seus direitos humanos ${ }^{13}$. Para tanto, a soberania em decidir suas questões internas, por parte dos Estados, vê-se mitigada, tendo em vista que aos seus nacionais se permite à busca de uma proteção internacional que garanta a efetividade dos direitos fundamentais, o que demonstra o enlace internacional direto dos direitos internos com àqueles que já são consagrados como garantidores da dignidade da pessoa humana na ordem internacional.

Os Estados modernos, ao entabularem seus textos constitucionais, principalmente no período pós-guerra, preocuparam-se em proteger os direitos humanos, até porque com a ideia de transconstitucionalização não seria possível que uma nação se fechasse aos núcleos protetivos existentes nas comunidades internacionais. Desta feita percebe-se uma relação cada vez mais transversal entre os Estados no tocante à consecução e garantia dos Direitos Humanos ${ }^{14}$.

\footnotetext{
${ }^{13}$ VARELLA, Marcelo D. Direito Internacional Público. 4ạ Ed. São Paulo: Saraiva, 2012, p. 29.

${ }^{14}$ NEVES, Marcelo. Transconstitucionalismo. São Paulo: Martins Fontes, 2009, p. 21
} 
Algumas barreiras naturais acabam por impedir uma aplicabilidade prática robusta dos direitos humanos frente aos diversos Estados, pois, mesmo tendo aplicação ultrafronteiriça, vista como universal àqueles atores que os ratificam, esta universalidade muitas vezes se apresenta apenas como um mero formalismo, que, na prática, acaba por ser mitigada em detrimento de interesses estatais. Para que haja uma real efetividade e posterior aplicabilidade do transconstitucionalismo é essencial que os direitos humanos não sejam apenas universais e sim verdadeiros entes multiculturais, pois desta maneira englobariam as diferentes nuances sociais existentes em cada diferente sociedade ${ }^{15}$.

Sob essa premissa, percebe-se que os esforços da comunidade internacional, deveriam ser no sentido de aproximar, não só o texto constitucional, como também os núcleos culturais comuns, a fim de que haja um diálogo mais profícuo e volumoso quanto à real eficácia da aplicabilidade interna dos direitos humanos, que ali são conhecidos como fundamentais.

Nesta senda, parte-se da ideia de que a garantia de dignidade da pessoa humana é algo basilar nos ordenamentos jurídicos com caráter humano transversal, e a garantia de tal princípio deveria figurar como a própria função social das constituições, tendo em vista que não se pode conseguir resultados satisfatórios inerentes aos direitos humanos se não houverem mecanismos que protejam o referido princípio no ordenamento interno ${ }^{16}$.

No que tange à importância constitucional na efetivação dos direitos humanos no ordenamento jurídico interno dos Estados, têm-se a ideia de que as constituições já foram consideradas como as legislações mais importantes dos ordenamentos jurídicos, no entanto, com a atual amplitude alcançada pela matéria, alguns ordenamentos existentes na senda internacional começaram a ter maior relevância interna, ou seja, os ordenamentos internacionais e comunitários acabaram por se equiparar àquilo que está previsto nos rincões constitucionais, tendo em vista a relevância da matéria ora dissertada ${ }^{17}$. Percebe-se, portanto, que a transconstitucionalidade trouxe ao âmbito interno noções de ordenamentos internacionais que já são mais maduros e preparados para a implementação de regras gerais que possibilitem ao cidadão local ter uma vida mais digna.

15 SANTOS, Boaventura de Souza. Para uma concepção intercultural dos direitos humanos. In: SARMENTO, Daniela e PIOVESAN, Flávia. Igualdade, diferença e direitos humanos. Rio de Janeiro: Lúmen Júris, 2010, p. 26

${ }^{16}$ SARLET, Ingo Wolfgang, Luiz Guilherme Marinoni e Daniel Mitidiero. Curso de direito constitucional. 6a Ed., São Paulo: Saraiva, 2017, p. 283.

${ }^{17}$ CANOTILHO, José Joaquim Gomes. Direito Constitucional e Teoria da Constituição. 3a Ed., Coimbra: Editora Almeida, 1998, p. 675. 
A estrutura de um Estado Social, defendida por Sundfeld (2009), mostra que o âmbito interno tem parâmetros de desenvolvimento próprio com focos e alicerces pessoais onde o Estado, embora seja mantido pelo povo, tem o dever de conceder a este uma condição social condigna, possibilitando àqueles que se sintam desprestigiados a luta pela efetividade de seus direitos básicos, no entanto, o mesmo Estado garantidor de direitos básicos deve estar aberto para ser questionado quanto à eficácia desses direitos, pois se este, além de não os garantir, não permitir o acesso do cidadão aos questionamentos dessa ineficácia, fatalmente estará agindo de forma contrária aos pisos de Direitos Humanos estabelecidos nos ordenamentos transestatais ${ }^{18}$.

Um fator que acaba por ter relevância quando se trata da ideia de transconstitucionalismo no âmbito interno dos países é a forma como o poder judiciário pode possibilitar aos indivíduos que se garantam os direitos básicos inerentes à pessoa humana, tendo em vista que os tribunais nacionais tendem a velar pela ordem constitucional interna e se esta contiver direitos fundamentais, como hodiernamente ocorre, caberia ao poder judiciário conferir a garantia de ocorrência e consecução de tais direitos ${ }^{19}$.

\section{O MERCADO COMUM DO SUL E OS DIREITOS HUMANOS}

A ideia de concepção do MERCOSUL se desenvolveu a partir do momento em que o mundo começou a fortalecer blocos econômicos regionais, tendo em vista a similaridade dos países envolvidos e a necessidade de se fortalecer as regiões para que se aumente, em conjunto a competitividade com o restante do globo. Para tanto, fora necessário que se construísse uma estrutura que adequasse as castas de cada um dos países componentes de dadas regiões para que se unificassem as ideologias centrais, até porque em matéria internacional o que se buscavam eram acordos que fossem benéficos à todos os componentes do bloco ${ }^{20}$.

Com a percepção dos Estados de que havia a proeminente necessidade de sair de um pensamento unicista onde um país, soberana e autonomamente, buscava seu desenvolvimento,

\footnotetext{
18 SUNDFELD, Carlos Ari. Fundamentos de direito público. 4a Ed. 10a tiragem. São Paulo: Malheiros, 2009, p. 56.

${ }^{19}$ MARTINS, Flávio. Curso de Direito Constitucional. 1a Ed. São Paulo: Revista dos Tribunais, 2017, p. 1.327.

${ }^{20}$ AMARAL JÚNIOR, Alberto do. Curso de Direito Internacional Público. 3ạ Ed. São Paulo: Atlas, 2012, p. 452.
} 
e ingressar em uma ideia conjunta, focada na concepção regionalista onde os blocos deveriam se fortalecer para conseguir melhores resultados para os indivíduos que o compunham.

Em um caráter embrionário na integração entre os Estados integrantes da América do Sul, no ano de 1960 fora assinado, por 11 países, o tratado de Montevidéu (TM-60), que visava ao estabelecimento e a criação da ALALC - Associação Latino-Americana de Livre Comércio onde o principal objetivo centrava-se em um acordo, em âmbito regional, no sentido de estabelecer entre os países componentes da América Latina uma zona de livre comércio, no entanto o seu período inicial seria de 12 anos, neste período sobressaíram-se no grupo o Brasil, Argentina e México, embora, entre eles, houvessem inúmeras diferenças ideológicas ${ }^{21}$.

A ideia central da ALALC era o fortalecimento do grupo econômico, visando a uma equiparação com outros blocos econômicos que já se firmavam pela Europa e Ásia, trazendo aos seus componentes resultados amplos que, certamente, agindo de forma unilateral não conseguiriam.

No mesmo norte, também em Montevidéu, mas já no ano de 1980 fora assinado mais um tratado (TM-80) onde neste se criou o ALADI - Associação Latino Americana de Desenvolvimento e Integração - no entanto, em contrário sentido do tratado anterior, a ALADI mitigava a visão regional e estabelecia uma necessidade de se reforçar individualmente cada estado que lhe integrasse para que, ao final, se obtivesse um prêmio coletivo ${ }^{22}$.

Com a ideia de se formar um bloco econômico que propiciasse o desenvolvimento integralizado de seus integrantes em 26 de março de 1991, em Assunção, fora celebrado o tratado que criou o MERCOSUL - Mercado Comum do Sul - em substituição a extinta ALADI, tendo como membros originais a Argentina, Brasil, Paraguai e Uruguai, no entanto somente em 1995 com a entrada em vigor do chamado protocolo de Ouro Preto, foi que o MERCOSUL recebeu a personalidade jurídica própria, sendo alçado à condição de Organização Internacional, fazendo com que os seus Estados integrantes passassem a ser denominados como Estados-membros ${ }^{23}$.

Com a criação do MERCOSUL objetivou-se a modernização interna de seus membros, bem como o aumento da competitividade internacional daqueles que dele faziam parte, mas, pode-se dizer, que a sua criação só fora possível em virtude da implementação da democracia

\footnotetext{
${ }^{21}$ HUSEK, Carlos Roberto. Curso de direito internacional público. 14ạ Ed. São Paulo: LTr, 2017, p. 268.

22 Idem, p. 268.

${ }^{23}$ VARELA, Marcelo D. Direito Internacional Público. 4ạ Ed. São Paulo: Saraiva, 2012, p. 349.
} 
no Brasil e na Argentina, pois são as principais economias do bloco, até porque até meados da década de 1970 os países se tratavam de forma hostil junto à comunidade internacional ${ }^{24}$.

Percebe-se que se torna essencial o alinhamento político para que se assegure a consecução de resultados comuns para os blocos econômicos, tendo em vista que em ambientes regionais, qualquer deslize cometido por um dos atores implica na perda de direcionamento de todo o bloco.

A necessidade de criação do MERCOSUL era tão grande, que os países que dele participavam pouco se importaram, ao criá-lo, em estabelecer critérios políticos concretos, bem como medidas práticas que equilibrassem as ações, principalmente, de Brasil e Argentina. Embora fosse senso comum que os países latino-americanos estivessem transitando de regimes autoritários para regimes democráticos e a possibilidade de cessão de parte de suas soberanias para o fortalecimento do bloco passava a ser algo bem mais palatável do que o fora em outros momentos.

Inicialmente, o MERCOSUL foi criado para atender aos objetivos dos países que originariamente the deram viabilidade, mas, no mês de dezembro de 2005, a Venezuela foi aceita no bloco, após a aprovação dos demais membros, ressaltando-se que os critérios de ingresso no bloco não se mostravam objetivos, e nem se vislumbrava uma perspectiva tão clara de como seria tal entrada.

No caso da aceitação da Venezuela como Estado membro componente do MERCOSUL, percebeu-se a ideia latente de necessidade de expansão do bloco, no sentido de trazer ao mesmo uma maior similaridade entre as economias envolvidas, uma vez que em comparação ao Brasil e Argentina as economias de Paraguai e Uruguai possuem um abismo de diferenças. Deste modo, com a entrada da Venezuela possibilitou-se que ocorressem diálogos mais próximos com outros Estados não integrantes, até porque o bloco mantém relações comerciais estreitas com países como Bolívia, Chile, Equador, Colômbia e Peru, classificando-os como membros associados, além do México que possui condição de observador ${ }^{25}$.

O principal objetivo do MERCOSUL visava a uma maior abertura aduaneira entre os países nele envolvidos, assim, percebe-se que este bloco, ao contrário do bloco europeu, não possui regras pormenorizadas de objetivos financeiros entre os seus componentes. Por outro lado, a partir da criação da sua personalidade jurídica, o bloco econômico passou a perseguir

\footnotetext{
${ }^{24}$ AMARAL JÚNIOR, Alberto do. Curso de Direito Internacional Público. 3a Ed. São Paulo: Atlas, 2012, p. 457.

${ }^{25}$ AMARAL JÚNIOR, Alberto do. Curso de Direito Internacional Público. 3a Ed. São Paulo: Atlas, 2012, p. 459.
} 
objetivos diretos de seus componentes, fazendo acordos e tratados no sentido de conseguir os melhores resultados possíveis para aqueles que dele fizessem parte ${ }^{26}$. Insta asseverar que até o presente momento o bloco econômico vem buscando modos de viabilizar o livre comércio entre os seus integrantes, haja vista que esta era a ideia embrionária do mesmo.

Ocorre que, mesmo buscando uma maior dinamicidade, o MERCOSUL não pode ficar alheio ao cenário internacional, principalmente no que se refere a Estados-membros. A crise enfrentada pela Venezuela fora interpretada pelos demais membros como algo que a fizera perder condições políticas tornando o país desinteressante para a integração do bloco. Como punição, em 02 de dezembro de 2016 o país recebeu a primeira suspensão por tempo indeterminado considerando que não iria conseguir cumprir com os compromissos assumidos no seu protocolo de adesão ${ }^{27}$.

Já no dia 05 de agosto de 2017, a Venezuela foi novamente suspensa do bloco por tempo indeterminado até que consiga demonstrar estar em condições políticas suficientes para manter sua ordem democrática ${ }^{28}$.

Para que haja a reinclusão da Venezuela no bloco muitos problemas deverão ser sanados, uma vez que as duas suspensões por tempo indeterminado, por motivos distintos, demonstram que o país para se manter interessante como membro deve estar fortificado, tanto na senda internacional como no plano interno. Ressalte-se que com a suspensão ela perde o direito de participar das decisões do bloco até que se restaure as questões problemáticas por ela enfrentada.

O caso venezuelano é emblemático, pois os demais países integrantes do MERCOSUL, através de seus porta-vozes ao justificarem a suspensão do país por ruptura da ordem democrática foram bastante enfáticos em afirmar que um país que não esteja observando os direitos humanos na sua seara interna não teria como ser aceito no bloco, por mais que isto signifique perde de comércio e mercado a todos os demais partícipes. Assim, percebe-se que na contemporaneidade, os direitos humanos têm se sobreposto aos interesses mais profícuos do Estado, como a própria geração de riquezas, tendo em vista que em detrimento da diminuição

\footnotetext{
26 PORTELA, Paulo Henrique Gonçalves Portela. Direito Internacional Público e Privado. 7ạ Ed. Salvador: JusPodium, 2015, p. 499.

${ }^{27}$ MARCO, Daniel Garcia: Qué consecuencias reales tiene para Venezuela la suspensión de Mercosur. BBC Mundo Caracas. 2016. Disponível em: http://www.bbc.com/mundo/noticias-america-latina-38190988. Acesso em: 24 de janeiro de 2018.

${ }^{28}$ BRASIL. 2017. Disponível em: http://www.mercosur.int/innovaportal/v/8469/11/innova.front/decisionsobre-la-suspension-de-la-republica-bolivariana-de-venezuela-en-el-mercosur. Acesso em: 24 de janeiro de 2018.
} 
de mercado, os países suspenderam um parceiro comercial em face de graves atentados que feriam a dignidade da pessoa humana em seu âmbito interno. Nesse sentido, as palavras do chanceler argentino Jorge Faurie são enfáticas: "Não importa o que se perca de comércio. 0 que estamos a dizer aqui é: você não pode matar seu povo, não pode cassar direito" 29 .

Na linha do que fora dito pelo chanceler argentino, pode-se perceber que a integração de qualquer bloco econômico que surja no cenário internacional não permite que o país venha a ferir os direitos humanos, uma vez que a comunidade internacional tem se preocupado cada vez mais com os núcleos constitucionais humanitários, impossibilitando o comércio destes atores, e, muitas vezes, aplicando sanções aos países que deliberadamente causem danos à dignidade da pessoa humana de seu povo.

Os líderes governamentais dos mais diversos Estados ocidentais do mundo não podem ficar alheios à opinião pública quanto à sua observância dos direitos humanos, deste modo, seria inconcebível imaginar um Estado que apoiasse um regime que não respeita os ditames da democracia, muitas vezes não porque o Estado de fato se importe com as barbáries que assolam a população do outro, mas porque em seu âmbito interno e perante a comunidade internacional o simples fato de se omitir quanto às condutas atentatórias quanto à própria humanidade pode lhe trazer consequências negativas, tanto em escala comercial quanto em escala política, até porque encontrar aliados que não se preocupam em manter uma imagem polida frente à sua população está cada vez mais escasso na era contemporânea.

Com o intuito de cooperar com os objetivos estatais outros atores internacionais, figurantes do terceiro setor, acabam por emergir não fazendo parte direta nem da sociedade civil nem do Estado, mas exercendo forte influência internacional através de organismos como as ONGs - Organizações Não Governamentais - frente aos reais atores partícipes dos embates internacionais ${ }^{30}$. As ONGs possuem papel fundamental na batalha de proteção aos direitos humanos, uma vez que agem diretamente junto aos Estados para que estes não venham a, deliberadamente, cometer atentados contra a sua população.

Ao se falar do MERCOSUL o mesmo, durante seu período de existência, tem se inclinado a buscar a proteção dos Direitos Humanos, o que pode ser percebido no regulamento de elaboração da Comissão Parlamentar Conjunta, datado de 03 de agosto de 1995, em Assunção, onde se buscou a paz, a liberdade a democracia e a vigência dos demais direitos humanos, e no

29 BAZZO, Gabriela e FRANCO Marina. G1, 2017. Disponível em: https://g1.globo.com/mundo/noticia/mercosul-suspende-direitos-politicos-da-venezuela-por-ruptura-daordem-democratica.ghtml. Acesso em: 24 de janeiro de 2018.

30 VARELA, Marcelo D. Direito Internacional Público. 4ạ Ed. São Paulo: Saraiva, 2012, ps. 437 e 438. 
mesmo ano ao se elaborar o acordo de cooperação entre União Européia e MERCOSUL se reafirma o compromisso de seus Estados-membros em observar as regras gerais inerentes aos Direitos Humanos ${ }^{31}$.

O objetivo inicial do MERCOSUL era o livre comércio entre os seus integrantes e, pouco se discorreu sobre Direitos Humanos nos debates embrionários que the deram fortitude, no entanto, a partir do momento em que o bloco passa a ser uma pessoa jurídica, como atributos de sua personalidade emana a ideia de observância direta dos direitos da pessoa, até porque se de suas ações forem gerados danos aos indivíduos este deverá arcar diretamente pelo dano por ele causado. A personificação do bloco fez com que este, naturalmente, se submetesse a figura das responsabilidades civis inerente às pessoas no âmbito interno dos Estados, responsabilidades estas que podem ser apuradas até mesmo no que se refere à inobservância de direitos humanos ${ }^{32}$.

Um ponto importante é que os direitos humanos servem não apenas para a proteção direta entre os indivíduos de um determinado Estado, como também orientam a integração entre indivíduos. Percebe-se que, no bloco econômico, principalmente com o claro objetivo como o estabelecido no MERCOSUL de livre comércio entre os seus integrantes, presume-se, também, o livre trânsito entre os Estados, o que causa toda uma preocupação entre os Estadosmembros se o seu cidadão estaria sendo respeitado como pessoa humana naquele Estado destino, ou seja, com o aumento do fluxo de pessoas transitando entre os Estados, os núcleos humanísticos comuns deveriam ser acentuados para garantir aos integrantes que estes poderiam ter certeza que nenhum mal ao seu povo estaria sendo gerado quando este se deslocasse.

Nesta senda, os direitos à propriedade, e aqueles inerentes à pessoa deveriam ser robustamente fortificados pelos Estados-membros, pois de outro modo um cenário de medo tomaria conta de todos os participantes do grupo. Claramente, têm-se mais uma justificativa para a suspensão da Venezuela, tendo em vista que no âmbito interno não se garantem os direitos humanos básicos inerentes às pessoas que ali residem ou transitam.

\footnotetext{
${ }^{31}$ MERCOSUL: legislação e textos básicos. - 5.ed. - Brasília: Senado Federal. Secretaria Especial de Editoração e Publicações, 2011. Disponível em: http://www2.camara.leg.br/atividadelegislativa/comissoes/comissoes-mistas/cpcms/arquivos/mercosul-legislacao-e-textos-basicos. Acesso em: 26 de janeiro de 2018.

32 TARTUCE, Flávio. Direito civil, Volume 2: direito das obrigações e responsabilidade civil. 12a Ed., Rio de Janeiro: Forense, 2017, p. 433.
} 
Como caráter comparativo, na Europa, já na edição do Tratado de Roma, que estabeleceu o atual mercado comum europeu, já se preocupavam com a regulamentação de direitos humanos, tendo em vista que a Corte Europeia de Direitos Humanos já tinha alicerces robustos definidos naquela seara internacional. Infere-se que naquele momento histórico as constituições dos países europeus já estavam comprometidas em garantir os Direitos Humanos na seara interna, inclusive com o proeminente entendimento que para ter sucesso no bloco econômico seria necessário que se entendesse que o direito comunitário internacional deveria prevalecer sobre o direito interno caso este atentasse de alguma forma contra aquilo que estava pacificamente entendido junto aos pares ${ }^{33}$.

O problema da praticidade de se aliar ao MERCOSUL um pensamento similar ao Europeu é que os países que o integram saiam de ditaduras militares, e neste período pouco se explorou em critérios inerentes aos direitos humanos, assim, a consecução de um núcleo básico comum focado na proteção de tais direitos seria um tanto quanto forçoso para a época.

Os direitos humanos são instrumentos integradores que reúnem diversos ordenamentos jurídicos e no MERCOSUL não seria diferente, uma vez que os países integrantes, ao elaborarem o Tratado de Assunção, instrumento idealizador do bloco econômico em apreço, já na introdução aos seus artigos estabelecem que a instituição do bloco serviria como um instrumento integrador dos povos que dele fizessem parte, demonstrando que, embora seu foco fosse eminentemente financeiro, essa integração populacional deveria de certo ocorrer ${ }^{34}$.

A comunidade internacional muito tem debatido sobre a necessidade de aplicação de direitos humanos para possibilitar o fortalecimento dos blocos, não economicamente falando, mas sim com o intuito de melhorar as condições de vida das populações dos Estados integrantes das diversas comunidades ora existentes.

Os Direitos Humanos podem ser definidos como o conjunto de regras jurídicas que permitam a pessoa humana a possibilidade de ter uma vida digna, nos termos e padrões existentes em determinado período histórico, sendo tais direitos tratados como indispensáveis para a coexistência harmônica entre os iguais de uma sociedade ${ }^{35}$.

A definição de Direitos Humanas frente a um cenário internacional possibilita a percepção da relação íntima existente das posições dos Estados na busca pelos ganhos econômicos e o resultado que essas ações trariam para a população dos Estados envolvidos. A

\footnotetext{
33 VARELA, Marcelo D. Direito Internacional Público. 4ạ Ed., São Paulo: Saraiva, 2012, p. 442.

34 BRASIL. 1991. Disponível em: http://www.planalto.gov.br/ccivil_03/decreto/1990-1994/d0350.htm. Acesso em: 24 de janeiro de 2018.

${ }^{35}$ RAMOS, André de Carvalho. Curso de Direitos Humanos. 4a Ed., São Paulo: Saraiva, 2017, p.21.
} 
comunidade internacional está focada em estabelecer diretrizes que possibilitem cuidados mínimos com a população dos países, tal preocupação está refletida nos fortes blocos estabelecidos em torno do globo terrestre, pois não se admite uma relação estreita entre governos que são antagônicos quanto às medidas protetivas frente a sua estrutura populacional.

Para que fosse possível sobrepujar o interesse internacional sobre o interesse interno, em se tratando de direitos humanos, fora necessário que se estabelecessem normas gerais aplicáveis a toda comunidade e que tais normas tivessem força no ordenamento jurídico individual de cada país, trazendo uma real superioridade hierárquica das regras internacionais frente as normas específicas de cada país ${ }^{36}$.

O problema de tal premissa reside na ideia de que não é simples forçar a um ordenamento jurídico interno que aplique normas de caráter internacional, esbarrando sempre na soberania das nações, mas os esforços internacionais na elaboração dos tratados e acordos são cada vez mais centralizados em tais resultados, buscando sempre estabelecer regras e procedimentos que possibilitem à comunidade internacional fiscalizar o Estado que dela fizer parte e até mesmo impor sanções para correção dos atos.

A eficácia prática dos direitos humanos em âmbito interno padece se houver choque com os direitos fundamentais específicos de um dado país, entendendo, para tanto, que os direitos humanos estão para as comunidades internacionais assim como os direitos fundamentais estão para os ordenamentos jurídicos internos. Ou seja, dificilmente um juiz de um Estado aplicaria uma ordem internacional inerente aos direitos humanos se essa ferisse um direito fundamental específico do país ${ }^{37}$.

As comunidades internacionais fazem uso de todos os mecanismos coercitivos que têm para forçar os Estados a cumprirem com suas deliberações, no entanto, tais mecanismos, nem sempre possuem eficácia imediata, pois esbarram nas soberanias das nações. Por outro lado, o Estado que der as costas para as sanções internacionais acaba por ficar alheio aos negócios que os demais atores internacionais estão por desenvolver e, por não possuírem autossuficiência

\footnotetext{
${ }^{36}$ COSTA, José Augusto Fontoura. Aplicabilidade direta do direito supranacional. In: CASELLA, Paulo Borba; Contratos Internacionais e direito econômico no MERCOSUL após o término do período de transição. São Paulo: LTR, 1996, p. 536.

37 MARQUES, Eduardo Lorenzetti. Direitos humanos no Mercosul. In: CASELLA, Paulo Borba. Mercosul Integração Regional e Globalização. Rio de Janeiro e São Paulo: Renovar, 2000, p. 537.
} 
para uma completa gestão, se faz necessária uma observância frente àquilo que se apresenta nas comunidades externas.

A necessidade de uma comunidade internacional com ideias unificadas frente aos direitos humanos alia-se à teoria de que os países que não se atentarem à proteção do ser humano ficarão cada vez mais isolados, com um número restrito de parceiros, o que os faria perder força econômica. Por outro lado, ao fortalecer os direitos humanos e permitir que se fiscalize aquilo que se faz em âmbito nacional o país demonstra que neste ponto seus parceiros comerciais teriam a plena convicção de que não estariam fomentando atrocidades frente a qualquer povo que seja.

\section{A DEMOCRACIA E O MERCOSUL}

Após a suspensão da Venezuela do MERCOSUL, uma notória necessidade culminou por ser destacada, atrelando a importância dos Direitos Humanos nos blocos eminentemente econômicos. Tal alarde se faz necessário, pois por se tratar de área cujo o objeto é o desenvolvimento de políticas internacionais que visem vantagens econômicas, não é comum que se discutam questões atreladas aos direitos Humanos.

Ocorre que, para que haja um ambiente favorável para investimentos externos é necessária uma harmonia inerente a garantia dos direitos humanos ante aos países integrantes do MERCOSUL, uma vez que se assim não fosse não haveria a possibilidade de criação de um espaço unificado plano, cujo o interesse em desenvolver uma cooperação técnica e política se sobressaísse a vontades internas.

Para a criação de regras gerais de Direitos Humanos em âmbito regional, como é o caso do MERCOSUL, existe o facilitador da proximidade cultural dos países integrantes, tal eixo denotaria a maior viabilidade de se estatuir as normas, até porque os interesses dos povos que fazem parte das nações que o integram, por regra, seriam bem próximos.

Em que pese a distância econômica ao qual o Brasil se espaça dos demais integrantes do bloco, é necessário que pontos culturais comuns sejam ressaltados, no intuito de fortalecer a unidade do bloco, e, posteriormente, possibilitar ao conjunto um engrandecimento coletivo, partindo da premissa que o desenvolvimento conjunto humanitário acabaria por agregar às individualidades participantes do bloco.

O caso Venezuelano demonstra a ruptura de um ponto sensível da relação entre países integrantes do MERCOSUL, uma vez que rompeu com a chamada "cláusula democrática", que 
fora incorporada ao Tratado de Assunção por força do Protocolo de Ushuaia, de 24 de julho de 1998, que estabeleceu já em seu artigo primeiro a importância da observância das instituições democráticas para reger as relações entre os países integrantes e a necessária permanência no bloco $^{38}$.

Como exposto por Gilberto Vergne Saboia em artigo científico que trata dos direitos humanos no MERCOSUL, a "cláusula democrática" redimensionou a importância dos Direitos Humanos no bloco, uma vez que denota o compromisso dos integrantes com a preservação da democracia interna ${ }^{39}$.

Ocorre que o respeito à democracia culmina na demonstração de uma amplitude de direitos que por sua subjetividade tornam-se barreiras para um controle eficaz, até porque as dificuldades enfrentadas ante ao âmbito social de cada país são de salutar relevância para a validação dos Direitos Humanos, sendo importante perceber que o Tratado de Ushuaia não adentra à miudeza do que seria a democracia, e, assim, seu espeque de possibilidades, por si só, já dificulta sua observância ${ }^{40}$.

Um entendimento basilar acerca do que seria a democracia salutar para que haja a garantia de observância dos Direitos Humanos no MERCOSUL. Norberto Bobbio trás dois curtos e importantes conceitos sobre o assunto dividindo a democracia em formal, que segundo ele seria "governo do povo", e substancial que seria "governo para o povo" ${ }^{41}$. Tal distinção, embora simplória, se faz necessária, uma vez que com a definição contida no tratado de Ushuaia não é possível que se delimite a extensão do que se busca, o que finalizaria por embotar o intento de garantir uma lisura democrática frente aos países integrantes do bloco.

A democracia factual seria aquela gerada por um governo estruturado no desenvolvimento humanístico de seu povo, sendo este sempre atento às necessidades populacionais. Percebe-se, portanto, que para haver um correto dimensionamento da atuação do Estado ante aos fatores democráticos que balizariam o tratado de Ushuaia, os integrantes do MERCOSUL deveriam garantir as premissas mais amplas do que seria a democracia.

Ocorre que para tal garantivismo dos Estados um enfrentamento necessário deveria ser desenvolvido, pois cada nação tem suas próprias particularidades e dificuldades, ou seja,

\footnotetext{
${ }^{38}$ BRASIL. 2002. Disponível em: http://www.planalto.gov.br/ccivil_03/decreto/2002/d4210.htm. Acesso em: 16 de maio de 2018.

${ }^{39}$ SABOIA, Gilberto Vergne. União Européia, Mercosul e a proteção dos direitos humanos. 2000.

${ }^{40}$ MONTE, D. Democracia e os movimentos de integração regional: a influência da cláusula democrática no Mercosul. 2015. Tese de Doutorado. Dissertação de Mestrado. Belo Horizonte: Pontifícia Universidade Católica de Minas Gerais. P.02.

${ }^{41}$ BOBBIO, Norberto. Dicionário de política. 12. ed. Brasília, DF: UnB. 2004, p. 328.
} 
deveria ser foco de o bloco evitar as crises democráticas para que este fosse cada vez mais longevo.

Uma noção da amplitude da dificuldade em prover os direitos humanos, tomando por base uma característica básica do Estado brasileiro, seria a própria forma federativa aqui presente, pois no momento em que a União passa a ser signatária de um tratado internacional de Direitos Humanos, automaticamente se compromete a garanti-lo em âmbito interno, sob pena de responsabilização internacional, o que a forma federativa acaba por dificultar ${ }^{42}$.

As temeridades enfrentadas pelo estado brasileiro são pontos perceptíveis, e no mesmo caminho os demais estados-membros também possuiriam reticências para estatuir uma regulamentação mais clara, e comprometedora, ante a aplicabilidade dos Direitos Humanos no MERCOSUL, aliás, o comprometimento de cada país volta a ser o ponto central da existência do bloco, tendo em vista que todos devem estar integrados na premissa de obter o melhor alcance econômico de suas ações; e porque não do melhor alcance humanístico de seus atos.

Ao imaginarmos que os países do MERCOSUL atravessaram momentos históricos de inobservância de direitos humanos bem similares, haja vista o período ditatorial enfrentado, vemos que a garantia internacional de que no plano interno vão ser oferecidos tais direitos ao povo é algo complexo e penoso de se fazer, uma vez que não há uma solidificação madura, nos moldes da Europa, por exemplo, de tais direitos nos Estados partícipes do bloco. E como pontuam as Organizações das Sociedades Civis (OSCS) presentes na área dos países relacionados ao bloco, os governos não são claros em transmitir a realidade da aplicabilidade dos Direitos Humanos nos seus territórios, deixando sempre uma impressão documental melhor do que a realidade enfrentada pela população ${ }^{43}$.

A atuação de entidades desvinculadas do Estado na percepção da proteção dos Direitos Humanos no bloco acaba por ser um balizador melhor do que as informações prestadas pelos membros, uma vez que tais entidades não estariam limitadas por dificuldades inerentes à atuação da máquina pública.

\footnotetext{
${ }^{42}$ BOBBIO, Norberto. Dicionário de política. 12. ed. Brasília, DF: UnB. 2004, p. 328.

${ }^{43}$ PITANGUY, Jacqueline; HERINGER, Rosana. Direitos humanos no Mercosul. Cadernos Fórum Civil, v. 3 , n. 4, p. 07, 2001.
} 
O ingresso da República Bolivariana da Venezuela no MERCOSUL, já fora algo temerário, pois naquele momento já se questionava a observância do país ao tratado democrático, gerando apreensão no bloco se estaria apta a dar lisura a proteção de tal direito do povo ${ }^{44}$.

Da mesma maneira que adentrou no bloco, sem haver, de fato, muitas garantias sobre a aplicação da democracia em seu território a Venezuela viu-se suspensa do mesmo, haja vista que não sustentou a pretensa política de governo popular que levantara em seu ingresso. Este caso tornou-se emblemático, pois houve uma notoriedade internacional sobre a crise democrática enfrentada. Em sentido contrário, evidencia um sinal de que é possível a fiscalização da aplicabilidade de Direitos Humanos para a preservação dos blocos econômicos e sua necessária observância, mas os estados-membros deveriam diminuir suas soberanias ao ponto de permitir um controle, de fato, efetivo no interior de suas fronteiras para que se garanta à comunidade internacional a perfeita harmonia deste rol de direitos em seus territórios ${ }^{45}$.

O risco que se tem é que a relativização da soberania da origem à celeumas internas, e tais desconfortos, mesmo que garantam uma sensação de tranquilidade à sociedade internacional, poderia ocasionar o desequilíbrio entre os Estados no médio e longo prazo, pois ao se sedimentar não seria possível mensurar todos os vieses de um abrandamento de uma base estatal tão profunda como a soberania.

\section{CONCLUSÕES}

No que tange ao MERCOSUL pode-se aplicar a teoria do transconstitucionalismo no sentido de alinhar os núcleos comuns referentes aos direitos humanos dos países integrantes, e deste núcleo um tratado em forma de declaração pudesse ser idealizado, ressaltando os direitos humanos dos povos integrantes dos países do bloco.

As declarações de direitos humanos que existem ao redor do mundo servem para possibilitar uma melhor aplicabilidade prática, gerando uma normatização positiva que, futuramente possa prover mecanismos de coerção para os Estados que não as observarem.

\footnotetext{
${ }^{44}$ GOMES, Eduardo Biacchi; CARTA WINTER, Luis Alexandre. Caminhos para a estabilidade democrática no Mercosul: A questão da Venezuela (The Path to a Democratic Stability in Mercosur: Venezuela's Case). 2015.

45 LAFER, Celso. Comercio, Desarmamento, Direitos Humanos: reflexões sobre uma experiência diplomática. São Paulo: Paz e Terra, 1998, p.150.
} 
O bloco que compõe o MERCOSUL busca a obtenção de ganhos econômicos, e essa característica do bloco faz com que esse pareça distante das regras norteadoras dos direitos humanos, no entanto, ao se aplicar uma suspensão à Venezuela, fundamentando na inobservância dos Direitos Humanos, percebe-se que não está assim tão dissociado de tais direitos.

A necessidade dos países, que são protagonistas no cenário internacional, é de sempre demonstrar uma maior lisura frente ao tratamento conferido aos seus cidadãos, possibilitando aos países coligados que esses não se preocupem caso um nacional de seu território passe a frequentar os domínios do país parceiro. Para que haja tal relacionamento é necessário que ambos os países estejam alinhados em torno das mesmas proteções aos seus povos e que demonstrem à comunidade internacional que são seguros para quaisquer relações que se estabeleçam além dos limites de suas fronteiras.

Os países integrantes do MERCOSUL estão imbuídos de muitos traços em comum no que tange às características populacionais, tendo em vista que todos eles partiram de colonizações europeias que ocorreram basicamente no mesmo período, fazendo com que as necessidades populacionais, além de muitos costumes, fossem alinhadas em torno dos mesmos eixos.

Partindo da premissa de que existem muitas características em comum nos povos dos países que compõem o bloco econômico em questão, percebe-se que seria possível que houvesse uma declaração dos direitos humanos específicos aplicáveis à tais países, e que desta declaração surgissem pactos protetivos às populações ora envolvidas.

O MERCOSUL surgiu como uma zona de livre comércio, idealizando de forma ampla a abertura de fronteiras entre os países integrantes, no entanto, com a consecução de tal objetivo, naturalmente as populações dos países começariam a se relacionar de forma mais direta, estabelecendo um laço comercial e de interação que não se pode medir de forma pragmática.

Como os países integrantes do bloco são democracias, com constituições fundamentadas em Direitos Humanos, o que se sugere é que se faça uma junção dos pontos em comum dessas constituições, no que tangem aos direitos humanos, e a partir desses pontos se efetive uma declaração com artigos claros, que sirva de orientação à todos aqueles Estados que já compõem o bloco econômico, mas também aos outros que tenham interesse em se associar ao mesmo, possibilitando uma maior clareza frente ao controle e ao que se espera de tais países. 
Para que haja uma longevidade e uma concreta materialização do que se objetivou com a criação do MERCOSUL, deve-se entender que naturalmente os seus povos cidadãos irão interagir entre si, estabelecendo relações que se distanciariam dos simples atos de comércio ${ }^{46}$, nesta seara, a observância dos Direitos Humanos, e a materialização de uma declaração unificada de quais seriam tais direitos possibilitaria que se punissem, de fato, aqueles países que não efetivassem a dignidade da pessoa humana de sua população.

No atual cenário internacional, não basta a um Estado tentar desenvolver sua economia de forma isolada, pois não existe a possibilidade de em um mundo globalizado, este ter $100 \%$ de autossuficiência em todos os ramos de sua atuação. A partir dessa premissa, se busca uma integração com outros Estados, e para que haja tal integração regras gerais deverão ser observadas, onde a soberania seja mitigada em prol de um objetivo único e integrador. No MERCOSUL, cabe aos seus integrantes respeitar as individualidades dos povos que o compõe, aplicando as regras básicas de Direitos Humanos, para possibilitar a integração dos cidadãos em torno de fronteiras realmente abertas, que tragam aos transeuntes a certeza de que onde quer que estejam suas individualidades serão respeitadas.

\section{REFERÊNCIAS}

AMARAL JÚNIOR, Alberto do. Curso de Direito Internacional Público. 3a Ed. São Paulo: Atlas, 2012.

BAZZO, Gabriela e FRANCO Marina. G1, 2017. Disponível em: $<$ https://g1.globo.com/mundo/noticia/mercosul-suspende-direitos-politicos-da-venezuela-porruptura-da-ordem-democratica.ghtml>. Acesso em: 24 de janeiro de 2018.

BRASIL. 2017 Disponível em: <http://www.mercosur.int/innovaportal/v/8469/11/innova.front/decision-sobre-la-suspensionde-la-republica-bolivariana-de-venezuela-en-el-mercosur>. Acesso em: 24 de janeiro de 2018.

BRASIL. 1991. Disponível em: <http://www.planalto.gov.br/ccivil_03/decreto/19901994/d0350.htm>. Acesso em: 24 de janeiro de 2018.

CANOTILHO, José Joaquim Gomes. Direito Constitucional e Teoria da Constituição. 3a Ed. Coimbra: Editora Almeida, 1998.

CARVALHO, Kildare Gonçalves. Direito Constitucional. 21a ed., Belo Horizonte: Del Rey, 2017.

\footnotetext{
${ }^{46}$ MARQUES, Eduardo Lorenzetti. Direitos humanos no Mercosul. In: CASELLA, Paulo Borba. Mercosul Integração Regional e Globalização. Rio de Janeiro e São Paulo: Renovar, 2000.
} 
COSTA, José Augusto Fontoura. Aplicabilidade direta do direito supranacional. Em CASELLA, Paulo Borba; Contratos Internacionais e direito econômico no MERCOSUL após o término do período de transição. São Paulo: LTR, 1996.

HUSEK, Carlos Roberto. Curso de direito internacional público. 14ạ Ed. São Paulo: LTr, 2017.

LASSALLE, Ferdinand. Digressão desenvolvida propedeuticamente por Ferdinand Lassalle em seus estudos, 1863.

MARCO, Daniel Garcia: Qué consecuencias reales tiene para Venezuela la suspensión de Mercosur. BBC Mundo Caracas. 2016. Disponível em: <http://www.bbc.com/mundo/noticiasamerica-latina-38190988>. Acesso em: 24 de janeiro de 2018.

MARTINS, Flávio. Curso de Direito Constitucional. 1a Ed. São Paulo: Revista dos Tribunais, 2017.

MARQUES, Eduardo Lorenzetti. Direitos humanos no Mercosul. In: CASELLA, Paulo Borba. Mercosul Integração Regional e Globalização. Rio de Janeiro e São Paulo: Renovar, 2000.

MENDES, Gilmar Ferreira e Paulo Gustavo Gonet Branco. Curso de Direito Constitucional. 12a Ed. Rev. e Atual. São Paulo: Saraiva, 2017.

NEVES, Marcelo. Transconstitucionalismo. São Paulo: Martins Fontes, 2009.

PORTELA, Paulo Henrique Gonçalves Portela. Direito Internacional Público e Privado. 7ạ Ed. Salvador: JusPodium, 2015.

RAMOS, André de Carvalho. Curso de Direitos Humanos. 4a ed., São Paulo: Saraiva, 2017.

SANTOS, Boaventura de Souza. Para uma concepção intercultural dos direitos humanos. In: SARMENTO, Daniela e PIOVESAN, Flávia. Igualdade, diferença e direitos humanos. Rio de Janeiro: Lúmen Júris, 2010.

SARLET, Ingo Wolfgang, Luiz Guilherme Marinoni e Daniel Mitidiero. Curso de direito constitucional. 6a ed., São Paulo: Saraiva, 2017.

SENADO Federal. Mercosul : legislação e textos básicos. - 5.ed. - Brasília: Senado Federal. Secretaria Especial de Editoração e Publicações, 2011. Disponível em: < http://www2.camara.leg.br/atividade-legislativa/comissoes/comissoes-

mistas/cpcms/arquivos/mercosul-legislacao-e-textos-basicos> Acesso em: 26 de janeiro de 2018.

SILVA, José Afonso da. Curso de Direito Constitucional Positivo. 31ạ ed., São Paulo: Malheiros, 2008.

SUNDFELD, Carlos Ari. Fundamentos de direito público. 4ạ ed., 10a tiragem. São Paulo: Malheiros, 2009.

TARTUCE, Flávio. Direito civil, Volume 2, Direito das obrigações e responsabilidade civil. 12a ed., Rio de Janeiro: Forense, 2017. 
UNIC, Rio. 2009. Disponível em: < http://www.onu.org.br/img/2014/09/DUDH.pdf>. Acesso em: 26 de janeiro de 2018.

VARELLA, Marcelo D. Direito Internacional Público. 4ạ ed., São Paulo: Saraiva, 2012.

Trabalho enviado em 20 de março de 2018.

Aceito em 22 de maio de 2018. 